\title{
O DOM QUIXOTE DE ANTÔNIO JOSÉ DA SILVA, AS MARIONETES DO BAIRRO ALTO E AS PRISÕES DA INOUISIÇÃO
}

Tradução de Estela Abreu

Em 1733, o Teatro do Bairro Alto de Lisboa apresentou, com suas marionetes, uma nova peça: a Vida do grande Dom Quixote de la Mancha e do gordo Sancho Pança. Era a primeira obra de um autor desconhecido, Antônio José da Silva. Em 1996, o diretor brasileiro Jom Tob Azulay fez O Judeu, filme sobre a vida trágica do dramaturgo, nascido no Rio de Janeiro de uma família de judeus convertidos e condenado à fogueira pelo tribunal da Inquisição de Lisboa em 1739. No filme há a reconstituição de duas cenas da peça como talvez tenham sido representadas pelas marionetes de Lisboa (Azulay, 1996). ${ }^{1}$ Na primeira, o cavaleiro errante e seu escudeiro encontram a companhia teatral de Angulo el Malo, que ia encenar o auto sacramental Las cortes de la muerte durante a festa de Corpus Christi. Na segunda, Sancho, governador da Ilha dos Lagartos (em Cervantes a Ilha da Barataria), comenta a alegoria da Justiça que é vesga e se atrapalha ao agir. Este último texto mostra bem a distância entre a adaptação de Antônio José da Silva e o texto do Dom Quixote: se o Sancho de Cervantes distribui bem (ou mal) a justiça, não explica em lugar algum por que ela é representada de olhos vendados e empunhando uma espada. Além disso, o cineasta deu livre curso à imaginação e se afastou do texto da peça: no fim do seu comentário, o Sancho de Azulay finge sodomizar a Justiça, ousadia que teria sido impossível na Lisboa de 1733.

A peça de Antônio José da Silva, conhecida por sua primeira edição impressa, lançada em Lisboa em 1744, se inscreve, primeiro, na história das adaptações teatrais da Segunda Parte de Don Quijote de la Mancha, publicada em Madri em 1615. ${ }^{2}$ A primeira foi do dramaturgo francês Daniel Guérin de Bouscal cuja Le Gouvernement de Sanche Pansa foi publicada em Paris em 1642 por dois livreiros do Palais, Antoine de Sommaville e Augustin Courbé. ${ }^{3}$ A peça era a última da trilogia quixotesca de Guérin de Bouscal, começada em 1640 com a dupla publicação de Dom Quixote de la Manche (que encenava, no seu último ato, vários episódios da Segunda Parte da história) $)^{4}$ e Dom Quichot de la Manche. Seconde Partie. ${ }^{5}$ Representada em 1641 e 1642, Le gouvernement de Sancho Pansa foi retomada por Molière quando ele se instalou em Paris em 
1658. Em seu livro Vie de Monsieur de Molière publicado em 1705, Grimarest menciona uma peça "chamada Dom-Quixote" na qual Molière desempenhava o papel de Sancho montado num burro que não quis entrar no palco. Isso deve ser uma referência à peça de Guérin de Bouscal visto que Grimarest assinala que "havia sido considerada no tempo em que D. Quixote instala Sancho Pança em seu Governo" (Grimarest, 1705). A peça deve ter agradado e foi encenada com frequência pela companhia de Molière: oito vezes em 1659, sete vezes em 1660, três vezes em 1661 e três vezes em 1662 (Forestier \& Bourqui, 2010: 1029-1052).

Alguns episódios da Segunda Parte, mas não o governo de Sancho Pança, foram introduzidos na terceira comédia espanhola inspirada por Don Quijote. As duas primeiras foram o Don Quijote de la Mancha de Guillén de Castro, peça escrita entre 1605 e 1608, publicada em 1618 (ver Chartier, 2011: 55-83), e a Don Quijote de Calderón de la Barca, representada no Buen Retiro em 1637, mas infelizmente perdida. A terceira adaptação, El Hidalgo de la Mancha, comédia escrita em colaboração com Juan de Matos Fragoso, Juan Bautista Diamante e Juan Vélez de Guevara, foi representada em 1676. Nunca foi impressa e só subsiste numa cópia manuscrita conservada em Viena (Martín, 1982).

Na França, os episódios do governo de Sancho inspiraram vários dramaturgos e foram encenados em diferentes gêneros dramáticos. Primeiro, no teatro de feira, com as peças compostas para as feiras parisienses por Bellavoine em 1705 ("Sancho Pança, peça em três atos representada pela companhia da viúva Maurice, na Feira Saint-Germain") e Fuzelier em 1710 (Arlequin et Scaramouche vendangeurs, designada como "Divertimento. Precedido de um Prólogo e seguido de Pierrot Sancho Pansa Governador da ilha da Barataria, executado no Grand Jeu do Préau da Foire Saint Laurent"). Nesta última peça, que se serve da pantomima, da dança e dos "letreiros" indicando as árias das partes musicais, a tomada de posse da ilha por Sancho é assim descrita pelo libreto: "Sancho Pansa que finalmente agarrou aquele governo tão desejado e tão bem pago por suas espáduas faz uma entrada ao som de instrumentos na Ilha da Barataria. Sancho vem montado no seu querido Grison. E ambos estão vestidos tal qual vem escrito nas fieis crônicas de Cid-Hamet-Benengely". ${ }^{6}$

A comédia é o segundo gênero que se refere ao governo de Sancho. Em sua Bibliothèque des théâtres, publicada em 1733, Maupoint (1733: 277-27) lembra que, depois daquela de Guérin de Bouscal, "as duas modernas são, uma a do Sr. Dufreny em três atos de Prosa não impressa em suas Obras ${ }^{7}$ e a outra a do Sr. Dancourt em cinco Atos de Versos representada no Mês de Novembro de 1712, sem muito êxito". Acusado de ter plagiado Guérin de Bouscal, Dancourt reconheceu, segundo Maupoint, "que tinha conservado alguns trechos de uma antiga Comédia de Sancho". Mandou interromper as representações e acrescentou novas cenas antes de entregar seu texto ao livreiro Ribou que o imprimiu. ${ }^{8}$ 
O governo paródico do governador Sancho inspira também comédias com música: em Paris, em 1727, La Bagatelle, opéra comique en deux actes, avec Prologue, ou Sancho Pança Gouverneur de Thierry e Gilliers (Parfaict, 1767: 348-351), ${ }^{9}$ e, na corte de Viena, no Teatrino di Corte, duas óperas compostas por Antonio Caldara sobre libretos de Giovanni Claudio Pasquini: em 1727, Don Chisciotte in corte della duchessa, designado como "opera serioridicola per musica" [ópera sério-ridícula com música], e, em 1733, Sancio Panza Governatore dell'isola Barattaria, definido como "commedia per musica". ${ }^{10}$

Quando Antônio José da Silva decidiu escrever o seu Dom Quixote para o teatro lisboeta do Bairro Alto, a Segunda Parte da história já havia portanto fornecido um riquíssimo material textual aos dramaturgos europeus e, especialmente, os capítulos XLII a LIII referentes ao governo de Sancho na ilha (que não é ilha) que lhe ofereceram como pilhéria o duque e a duquesa, irônicos anfitriões do cavaleiro errante e de seu criado escudeiro. A edição da história que ele utilizou foi forçamente em língua espanhola, pois a primeira tradução em português do Don Quijote só apareceu em 1794. Foi publicada em Lisboa sem o nome do tradutor com o título de O Engenhoso Fidalgo Dom Quichote de la Mancha (1794). É possível até afirmar que Antônio José da Silva possuía uma edição posterior a 1662 porque, no texto de sua peça, o livro que narra as aventuras e desventuras do cavaleiro errante é citado por Sancho como "A vida de vossa mercê", retomando assim o título da primeira edição que reúne as duas partes do livro, a Vida y hechos del Ingenioso Cavallero Don Quijote de la Mancha, publicada em Bruxelas em 1662 por Juan Mommarte. ${ }^{11}$ Esse título foi mantido em todas as edições seguintes, tanto em Antuérpia em 1672-1673 ${ }^{12}$ como em Madri nas quatro edições publicadas entre 1674 e $1723 .{ }^{13}$ Foi sem dúvida uma delas que Antônio José da Silva leu e aproveitou para compor a primeira de suas comédias representadas pelos bonecos do Teatro do Bairro Alto.

Esse teatro era um dos lugares onde os liboetas podiam, nas três primeiras décadas do século XVII, assistir a peças de teatro (ver Perkins, 2004: 57-69). Havia outros. As comédias das companhias espanholas eram apresentadas no Pátio das Arcas. Esse "pátio das comédias" pertencia ao Hospital Real de Todos os Santos que recebia importante parte das receitas. Foi fechado em 1727 após uma viva campanha promovida contra a imoralidade dos espetáculos teatrais e só recebeu novas comédias a partir de 1737. As óperas italianas, ou algumas de suas árias, eram cantadas por companhias itinerantes presentes em Lisboa desde 1731, mas só eram propostas no Palácio Real e nos teatros particulares pertencentes à aristocracia. Foi apenas em 1735 que a Academia da Trindade apresentou sua primeira ópera a um público mais amplo: o Farnace de Schiassi (Brito, 1989). ${ }^{14}$ O Teatro do Bairro Alto aproveitou então o encerramento do Pátio das Arcas e a ausência das apresentações públicas das óperas italianas para representar com seus bonecos uma peça de novo gênero. Estava assim inaugurada uma modalide dramática inédita em Lisboa, ao mesmo tempo comédia 
e ópera, que misturava diálogos em prosa com partes cantadas: árias, duetos, coros. E, desse modo, em Dom Quixote são cantados três coros, onze árias, um dueto e um canto a quatro vozes.

Apesar da imaginação cinematográfica de Tom Job Azulay, é difícil reconstituir com exatidão os dispositivos das representações do Teatro do Bairro Alto. Suas marionetes deviam ser bem parecidas com as das companhias que representavam as óperas italianas nos teatros particulares das aristocracias romana e veneziana ou em Paris e Viena quando lá faziam turnês (Jurkowski, 1996: 122-128). Essas marionetes eram manipuladas graças a fios amarrados em suas mãos e seus pés e uma haste de ferro que lhes entrava pela cabeça. A primeira descrição de tais "pupazzi" foi feita em 1645 pelo jesuíta italiano Giovanni Domenico Ottonelli em seu livro Della christiana moderatione del theatro (Ottonelli, 1645): "As figuras têm cabeça de papel machê, corpo e pernas de madeira, braços feitos com cordas, mãos e pés de chumbo". Ottonelli explica também que apenas um marionetista declama o texto de todos os personagens: "diante dele, há uma cópia marcada com várias cores que indicam as mudanças do tom de voz: o vermelho indica a voz de uma senhorita, o azul a de um homem e o verde a de um bufão" (Jurkowski, 1996: 94-97). Essas marionetes, tanto as dos italianos como as do Bairro Alto, eram diferentes de outras: aquelas que eram movidas nos trilhos traçados no próprio palco (Jurkowski, 1996: 121) e as que, graças a uma haste de ferro que lhes atravessava o corpo, eram manipuladas por um marionetista colocado abaixo do palco.

Em Lisboa, as marionetes designadas como figuras artificiais, bonecos ou bonifrates não eram de madeira e sim de cortiça. Sua leveza permitia movimentos espetaculares e rápidas "mutações" ou mudanças de cenário. Foi assim que, na primeira parte de Dom Quixote, os espectadores de 1733 podiam ver o cavaleiro errante matar o leão, entrar na gruta de Montesinos seguido de raios e do trovão, ou voar numa nuvem até o Parnaso. Essa forma de teatro era dirigida a uma plateia composta por membros da pequena nobreza e das burguesias citadinas. Não deve ser confundida com os espetáculos mais populares feitos com as marionetes de Mestre Pedro nos capítulos XXV e XXVI da Segunda Parte do Don Quichotte de Cervantes, nem com o "puppet show" ou "motion" representado no último ato de Bartholomew Fair, comédia de Ben Johnson encenada em 1614.

Mestre Pedro, aliás Ginés de Pasamonte, é um apresentador de marionetes "que há muito tempo percorre esta Mancha de Aragão, mostrando um retábulo da libertação de Melisandra pelo famoso Don Gaiferos" (Cervantes, 1998: 839839). No capítulo XXV de Don Quichotte, o retábulo é instalado na hospedaria e "Mestre Pedro se pôs dentro dele, porque devia manejar os personagens, e um rapaz, criado de Mestre Pedro, ficou de fora para servir de intérprete e explicar os mistérios do dito espetáculo". Mestre Pedro parece manejar suas marionetes por baixo e é dessa maneira que está representado numa ilustração da edição de Bruxelas da Vida y hechos del Ingenioso Cavallero Don Quijote de la Mancha de 
1662. É esse posicionamento que lhe salva a vida quando Dom Quixote corta em pedaços a "titereira mourama" que perseguia Melisandra e seu salvador e esposo, Don Gaifeiros: D. Quixote deu um tal golpe que, "se Mestre Pedro não se abaixa, encolhe e alapa, lhe teria cortado a cabeça com mais facilidade que se fosse de marzipã" (Cervantes, 1998: 850-851 e 310). Entretanto, é prudente evitar uma leitura demasiado "documental" do texto de Cervantes que atribui ao teatro de marionetes de Mestre Pedro capacidades cenográficas (por exemplo, a simultaneidade de várias ações) impossíveis para um único manipulador e que parecem referir-se mais aos retábulos de autômatos frequentes na Espanha. A imaginação de Cervantes talvez tenha misturado em sua descrição do retábulo essas duas formas de espetáculos sem atores. ${ }^{15}$

Na comédia de Ben Jonson, o "puppet master" Leatherhead, aliás Lantern, representa uma peça intitulada "ancient modern history of Hero and Leander, otherwise called The Touchstone of True Love", que é uma paródia do famoso poema de Marlowe publicado em 1598 (ver Gosset, 2000: 162-195). Ben Jonson utiliza esse divertimento familiar nas feiras, em Londres no século XVII como em Paris no século XVIII, para estabelecer um duplo paralelismo: entre as marionetes, que formam uma "civil company", e os artistas, que sempre reclamam, fazem pouco, insultam e se embebedam; entre a poesia, dramática ou não, e os espetáculos populares e vulgares, que rebaixam o teatro ao nível dos cães dançantes e exibições de animais monstruosos (Shershow, 1995: 56-66 e 99-106). Não é de todo fácil imaginar o "puppet show" proposto por Leatherhead. Como o "recitator" do teatro dos Antigos (pelo menos segundo a ideia que se tinha no Renascimento), ${ }^{16}$ ele declama as partes de todos os personagens a exemplo dos apresentadores de "pupazzi" italianos: "I am the mouth of them all" (Jurkowski, 1996: 110-112). Ele parece também partilhar a cena com as marionetes manipuladas por um assistente já que uma delas consegue bater nele. É portanto possível que, como em certas companhias de "commedia dell'arte", marionetes e atores representem uns com os outros, nos mesmos palcos (Jurkowski: 1996: 104-106). Tal dispositivo é sugerido no fim da peça: o diálogo entre Zeal-of-the-Land Busy, o puritano que interrompe a representação e quer interditar o teatro, considerado imoral e idólatra, e "Puppet Dionysius". Assim como o "motion of the Prodigal Son" mostrado por Autolycus, o mascate do Conto de inverno de Shakespeare, ${ }^{17}$ e como o retábulo de Mestre Pedro, o "puppet show" de Leatherhead participa da cultura carnavalesca da praça pública, das feiras e da itinerância. Os bonecos ou bonifrates de Lisboa pertencem a um mundo teatral de outro tipo.

A primeira vez que a Vida de Dom Quixote de 1733 foi atribuída a Antônio José da Silva foi no ano de 1741, ou seja, dois anos após a trágica morte do dramaturgo. Essa menção está na Bibliotheca lusitana de Diogo Barbosa Machado que indica em seu primeiro volume, à página 303: "Antonio Joseph da Silva natural do Rio de Janeiro filho de João Mendes da Silva, Advogado nesta Corte, e Lourença Coutinho, Estudou Direito Civel em a Universidade de Coimbra donde 
passando a Lisboa exercitava o officio de Advogado de Causas Forenses. Teve genio para a Poesia Comica” (Machado, 1965: 303). "Teve genio para a Poesia Comica": a Bibliotheca menciona, portanto, seis de suas comédias que foram encenadas com os "aplausos dos espectadores": três títulos são dados como tendo sido impressos, Labirinto de Creta em 1736, Variedades de Proteu e Guerras do Alecrim e Manjerona em 1737, e três outros são seguidos pelas duas letras M. S., isto é, essas peças permaneceram manuscritas: Anfitrião ou Júpiter e Alcmena, Vida do grande Dom Quixote de la Mancha e Precipício de Faetonte.

Em 1744, essas seis obras foram publicadas num volume intitulado Theatro cômico portuguez, acompanhadas de duas outras: Esopaiada, ou Vida de Esopo e Os encantos de Medeia que datariam respectivamente de 1734 e $1735 .{ }^{18}$ O nome do autor não aparece na folha de rosto, mas é facilmente decifrável pelo acróstico que termina o prefácio dedicado "ao leitor desapaixonado". Lidas verticalmente, as primeiras letras das primeiras palavras dos vinte versos das duas décimas finais indicam: ANTONIO JOSEPH DA SILVA.

Quem era Antônio José da Silva em 1733? Podemos seguir com precisão sua vida atormentada e seu destino infeliz graças aos dois magníficos livros de Nathan Wachtel, La foi du souvenir (2001: 298-318) e La logique des bûchers (2009: 84-98 e 128-141). Ele nascera em 1705 no Rio de Janeiro de uma família de "cristãos-novos", judeus forçados à conversão ao cristianismo após 1497 e chegados ao Brasil sem dúvida no início do século XVII. Em 1711, seus pais e grande parte da família foram denunciados à Inquisição como praticantes de ritos judaicos : jejuns rituais, proibições alimentares, porte de roupas limpas no sábado. Foram todos levados a Lisboa onde Antônio José chegou com os irmãos Balthazar e André. No cárcere, seus pais João e Lourença confessaram o retorno ao judaísmo. Em 9 de julho de 1713, por ocasião de um auto de fé, eles foram "reconciliados" com a Igreja e condenados ao confisco de seus bens e ao porte do hábito penitencial nos domingos e dias santos.

Esse primeiro encontro com o Tribunal da Inquisição lisboeta não foi o único. Em 1726, uma prima de Antônio José da Silva, Brites Coutinho, foi denunciada à Inquisição pelo noivo, Luís Terra Soares, estudante de direito canônico em Coimbra, que talvez também fosse "cristão-novo" e temesse pela própria vida. Antônio José foi preso com a mãe, com a tia Isabel Cardoso Coutinho, os dois irmãos e vários primos. Confessou seu retorno à "lei mosaica", denunciou outros parentes, mas não sua mãe e, por essa recusa, foi torturado. Ferido, não conseguiu assinar seu ato de abjuração - "por não poder assinar por causa de tormento". Ele foi "reconciliado" com a Igreja pelo auto de fé de 13 de outubro de 1726 e condenado ao confisco dos bens, ao hábito penitencial e a receber instrução cristã. ${ }^{19}$

Morando em Lisboa, Antônio José que, como o pai, era advogado, começou uma carreira literária. Compôs, além das oito "óperas" publicadas no livro lançado em 1744 que assim designa as suas "comédias", dois poemas publica- 
dos em 1736 com seu próprio nome em duas antologias que atestam suas ligações com a corte de D. João V e suas relações com membros da elite aristocrática. O primeiro poema, incluído na coletânea Acentos Saudosos das Musas Portuguesas, é uma glosa do soneto de Luís de Camões no qual Portugal expressa seu sentimento diante da morte de sua belíssima Infanta Senhora Dona Francisca. O segundo poema é um Romance héroïco em louvor de João Cardoso da Costa, cujos poemas estão reunidos no volume intitulado Musa Pueril. A reedição da Bibliotheca lusitana em 1759 também atribui a Antônio José da Silva uma "comédia de santo" em castelhano, El Prodigio de Amarante San Gonçalo, escrita em 1735 ou 1737, ${ }^{20}$ e que seria uma prova dada pelo dramaturgo da autenticidade de sua abjuração, e uma Sarzuela Epithalamica composta para o casamento do filho de D. João V com a filha de Filipe V da Espanha (ver Machado, 1759: 41). ${ }^{21}$

As relações com os poderosos não protegeram Antônio José de uma segunda detenção pela Inquisição. Em 1773, foi encarcerado com a esposa, Leonor Maria de Carvalho, e com a mãe, depois que seu irmão André e família foram denunciados como "judaizantes" por um novo cristão reconciliado a quem eles haviam dado abrigo. Encarcerado durante dois anos, enquanto era representada no Teatro do Bairro Alto sua última ópera, O Precipício de Faetonte, Antônio José causou sua própria desgraça. Negou todas as acusações que lhe foram feitas, mas foi denunciado pelos espiões que o vigiavam por buracos feitos nas paredes e por colegas de cela delatores. Afirmaram que ele observava os jejuns do judaísmo, que não sabia fazer direito os gestos cristãos e zombara das orações de um dos colegas de cela. Os depoimentos favoráveis de três dominicanos e de um agostiniano que afirmaram ser ele um bom cristão não impediram que ele fosse "declarado por convicto, negativo, pertinaz e relapso no crime de heresia e apostasia e que foi hereje apostato de Nossa Santa Fe Catolica". Entregue ao braço secular, foi estrangulado e queimado (o que era chamado "queimar de garrote" e considerado como um favor da Inquisição) depois do auto de fé de 16 de outubro de 1739 no qual sua mulher, sua mãe, seu irmão, sua cunhada e sua tia foram, mais uma vez, "reconciliados" com a Igreja, apesar do risco de alguns deles ainda serem considerados relapsos. ${ }^{22}$

Antes do exame das possíveis relações entre esse destino marcado por perseguições e as obras de Antônio José da Silva - em particular sua Vida do grande dom Quixote composta depois de seu primeiro processo, tortura e condenação - o estudo de duas cenas da primeira parte da ópera ajuda a compreender como o dramaturgo se serviu do texto de Cervantes para fazer uma peça teatral (Pereira, 2007: 77-148). ${ }^{23}$ Trata-se da oitava e da nona cenas da obra em que Don Quichotte e Sancho viajam até o Parnaso para satisfazer o pedido da musa Calíope que pediu ajuda ao cavaleiro errante a fim de combater os maus e malvados poetas unidos contra Apolo. A última cena desse Primeiro ato ou Primeira parte, a nona, mostra a batalha vencida por Don Quichotte contra os 
"poetazinhos" e termina com a ária burlesca de Sancho: "Se hoje o meu cantar / Um zurro há de ser, / quero começar: / an, an, an, an !”

No Don Quijote de Cervantes, não se encontra nenhuma "poetomaquia" semelhante ao combate encenado por Antônio José da Silva, e Don Quichotte não visita o Parnaso. Mas o dramaturgo conhecia bem o seu Cervantes e é em outra obra que ele busca sua invenção teatral: El viaje del Parnasso publicado em Madri em 1614 (ver, também, Gaos, 1973). ${ }^{24}$ Trata-se de um poema com mais de três mil versos que narra a viagem de Cervantes ao Parnaso e a batalha de livros entre os bons e os maus poetas. A obra pertence ao gênero das "viagens ao Parnaso" e imita explicitamente o Viaggio in Parnasso publicado por Cesare Caporali em $1582 .{ }^{25}$ Essa imitação permitia a Cervantes, ao mesmo tempo, uma sátira dos poetas de sua época, uma paródia burlesca da mitologia e uma autobiografia disfarçada (Canavaggio, 1981).

Antônio José da Silva se apossa sutilmente do poema de Cervantes. Em sua ópera, don Quichotte encontra Calíope, em vez de Mercúrio, como ocorre em Cervantes, o que abre a série de três árias cantadas pelas Musas, primeiro Calíope, depois Euterpe e Terpsicore. Essa viagem até o Parnaso se efetua voando numa nuvem, e não de barco, o que permite um efeito cênico mais espetacular. O dramaturgo português introduziu também na situação traços cômicos que apelam para a ilusão teatral e a "suspension of disbelief" requerida pela ficção. Quando Calíope aparece para Don Quichotte, este declara: "Soberana ninfa, / Echarpe de Íris deste horizonte. / Que rasgando as nuvens diáfanas... / Mostra tua divindade". Mas Sancho rompe o encantamento e acompanha cada exclamação de seu senhor com tiradas mais prosaicas: "Ninfa soberana / Arco-íris deste horizonte./ Que rasgando as nuvens de papelão... / Te ostentas já de idade”.

É esse mesmo procedimento que atribui ao Sancho de Antônio José o papel brechtiano de destruídor da ilusão. Assim, na sétima cena da Primeira Parte, enquanto para Don Quichotte a gruta de Montesinos é uma maravilha: "Vês, Sancho, que admirável palácio? Vês estas colunas dóricas e coríntias? Olha estes jaspes! Que te parece?, seu escudeiro o traz de volta à realidade - e ao teatro: "Parece-me que tudo isto é pintado em tábuas de pinho". E na primeira cena da Segunda Parte da peça, a D. Quixote que lhe pergunta: "Sabes onde estamos?" Sancho responde: "Sei muito bem. No Teatro do Bairro Alto".

Antônio José da Silva comprova o seu gênio teatral ao condensar a batalha entre os dois exércitos poéticos tal como é narrada, longamente, por Cervantes. A lista pormenorizada das armas poéticas de destruição maciça que ocupa os 361 versos do capítulo VII da Viaje al Parnasso é drasticamente resumida por Sancho que assim descreve o exército dos maus poetas: "Não está vendo o exército deles, com dez mil romances, quatro mil sonetos, duzentas décimas [estrofe de dez versos], oitenta madrigais e seu esquadrão de sátiros volantes em salva de silvas". O dramaturgo desloca assim certos motivos do poema: o ferimento na mão de Mercúrio, atingido por "una satira licenciosa / de estilo 
agudo, pero no muy sano" ["uma sátira libertina / de estilo agudo, mas não muito sadio"], é substituído pelo de Sancho: "Socorro, tenho um soneto com rimas tão pontiagudas que me furam de lado a lado".

Antônio José da Silva transforma os textos de Cervantes, tanto o de Don Quichotte quanto o de Viaje al Parnasso, para responder a duas exigências da peça que ele escrevia para o Teatro do Bairro Alto. De um lado, ela devia receber partes cantadas, cujo número cresceu nas óperas seguintes, para chegar a trinta e uma em Labirinto de Creta, em 1736, e trinta e duas em O Precipício de Faetonte, em 1738. O compositor da música e das árias da Vida do grande Dom Quixote não é conhecido, mas sabe-se que Antônio José colaborou com Antônio Teixeira para Os Encantos de Medeia, As Variedades de Proteu e as Guerras do Alecrim e Manjerona - e talvez, igualmente, para Anfitrião e Labirinto de Creta (Perkins, 2004: 47). Por outro lado, sua peça devia também aproveitar liberdades permitidas a um teatro de marionetes e mostrar aos espectadores maravilhados movimentos de cena espetaculares. Antônio José da Silva soube superar todas essas dificuldades com engenho, como mostram as outras sete peças compostas que lhe foram encomendadas ou que foram aceitas pelo Teatro do Bairro Alto entre 1734 e 1738.

Devem-se considerar certas invenções dramáticas ou poéticas de Antônio José da Silva como resquícios de sua própria experiência de "converso", sempre suspeitado pela Inquisição e brutalmente tratado durante o processo de 1726 ? É isso o que afirma a tradição brasileira que fez do dramaturgo um mártir da liberdade de crença, vítima do fanatismo católico e herói dos direitos da colônia, violados pela dominação da metrópole. A construção de Antônio José da Silva como herói e mártir começa em 1838 com a tragédia romântica de Domingos Gonçalves de Magalhães intitulada Antônio José ou O poeta e a Inquisição (1838; ver Lima, 2005 e Gomes, 2004), prossegue em 1866 com o romance de Camilo Castelo Branco, O Judeu, publicado em $1866^{26}$ e se encarna no século XX na narrativa dramática do dramaturgo português Bernardo Santareno, O Judeu (Santareno, 1966), e no filme de Jom Tob Azulay que tem o mesmo título. ${ }^{27}$

Terão os sofrimentos de Antônio José da Silva deixado marcas em suas peças ? Machado de Assis achava que não e estabelecia uma separação entre a apreciação das obras do dramaturgo e a emoção provocada por seu trágico destino. Como escreve Machado em seu artigo "Antônio José", incluído na coletânea Relíquias de Casa Velha: "A piedade não é decerto determinativa em pontos de crítica, e tal poetastro haverá que, sucumbindo a uma grande injustiça social, somente inspire compaixão sem desafiar a análise. Não é o caso de Antônio José: este mereceria por si só que o estudássemos, ainda despido das ocorrências trágicas que lhe circundam o nome" (Assis, 1979: 726). Machado de Assis nega assim qualquer intenção denunciadora ou trágica nas comédias de Antônio José da Silva, escritas com a mera finalidade de fazer rir, recorrendo até a elementos do "baixo-cômico". Para ele, "não obstante os vestígios e as lembranças desse primeiro ato da Inquisição [a condenação de 1726], não obstante o espetáculo 
do que padeciam os seus, as óperas de Antônio José trazem o sabor de uma mocidade imperturbavelmente feliz, a facécia grossa e petulante, tal como lhe pedia o paladar das plateias, e nenhum vislumbre do episódio trágico" (Assis, 1979: 733).

É esse mesmo distanciamento entre a vida e as obras que se encontra na tese de José Oliveira Barata, defendida em Coimbra e editada em dois volumes em 1983 e 1985 com o título Antônio José da Silva: criação e realidade (Barata, 1985). Num texto em francês, que serve de prefácio à tradução de quatro peças de Antônio José da Silva (entre as quais a Vida do grande Dom Quixote de la Mancha que citamos), o autor defende o que ele designa como uma "espécie de nova escolástica": "Visto que o judeu foi vítima da Inquisição, suas obras só podem refletir a animosidade contra seus ferozes perseguidores. Logo, ao ler superficialmente a obra, muitos julgam detectar os indícios da revolta do escritor contra uma instituição opressora" (Barata, 2000: 12). Três argumentos contrariam tal leitura: por um lado, não é feita nenhuma referência às peças de teatro nas acusações da Inquisição, e foi o mesmo Inquisidor Geral, o cardeal Nuno da Cunha, quem assinou a condenação de Antônio José em 1739 e concedeu a licença para a publicação de suas comédias em 1744; por outro lado, a prudência exigia uma forte autocensura da parte do dramaturgo e proibia qualquer alusão subversiva; enfim, todas as suas composições são retomadas paródicas de obras ou de histórias existentes, à exceção de Guerras do Alecrim e Manjerona, o que as inscreve na tradição teatral, e não na experiência vivida.

Mais recentemente, Nathan Wachtel e Paulo Roberto Pereira defenderam a ideia de que talvez fosse necessário rever essa revisão. Em seu magistral estudo sobre os "conversos" condenados como judaizantes pela Inquisição lisboeta, Nathan Wachtel indica a respeito de Antônio José da Silva de quem ele reconstituiu minuciosamente a prisão, o processo e o suplício entre 1737-1739, que: "um conjunto de argumentos razoáveis permite sustentar a tese segundo a qual Antônio José da Silva teria sido condenado em razão das ideias subversivas que o seu teatro passava para o público" (Wachtel, 2001: 313). Para ele, o gênero satírico não é nada exclusivo da crítica social, mesmo que esta deva ser enunciada num modo cômico e que o autor tenha de se resguardar por trás das tiradas burlescas de seus personagens. Mas, afirma Nathan Wachtel, "o fato é que se podem extrair das peças do 'Judeu' muitas citações que, situadas no contexto histórico, parecem confirmar uma rara temeridade, como a de fazer alusão à própria experiência nas prisões da Inquisição" (Wachtel, 2001: 313). Paulo Roberto Pereira indica, por seu lado, no Prefácio à edição portuguesa de quatro comédias de Antônio José da Silva, o caráter autobiográfico de certos trechos das peças (sobretudo Anfitrião) e a violência inusitada da sátira às instituições e à sociedade da época (Pereira, 2007: 30 e 34).

Para decidir entre essas diferentes afirmações, é preciso voltar ao texto. E, primeiro, às cenas da Vida do grande Dom Quixote de la Mancha em que Sancho 
comanda a justiça e faz comentário sobre a sua alegoria. Respeitando as necessidades dramáticas e fiel ao procedimento da condensação textual, Antônio José da Silva reduz a três princípios os múltiplos avisos dados por Dom Quixote a Sancho antes que este tome posse de sua ilha. O primeiro é aquele que exige a justiça: "Sancho, tem sempre em mente que vais governar: lembra-te que deves sempre ter diante dos olhos a Justiça”. A ordem é entendida literalmente por Sancho que responde: "Sim, meu senhor, vou pedir que me façam o retrato dela e vou pô-lo diante de meus olhos", o que anuncia o comentário que abre a quarta cena da Segunda Parte. As duas outras ordens do cavaleiro errante são: "Não te deixes corromper pelos presentes" e "Ama a Deus e a teu próximo como a ti mesmo".

A explicação da alegoria da Justiça é uma invenção de Antônio José da Silva, totalmente ausente no Don Quijote. Para Sancho, a Justiça "é coisa pintada", "e era necessário haver essa figura no mundo para meter medo à gente grande, como o papão às crianças". Ele explica em seguida o significado de cada um dos atributos de tal "figura": ela está "vestida à trágica, porque toda a justiça acaba em tragédia; taparam-lhe os olhos, porque dizem que era vesga e que metia um olho por outro; e, como a Justiça havia de sair direita, para não se lhe enxergar esta falta lhe cobriram depressa os olhos. A espada na mão significa que tudo há de levar à espada, que é o mesmo que a torto e a direito" e segura uma balança "que não tem fiel; nem fiador". Pintura ou alegoria, a Justiça é tão real quanto o bicho-papão ou a Dulcineia del Toboso.

Os casos julgados por Sancho na comédia são todos diferentes daqueles resolvidos pelo Sancho de Cervantes. Todos destacam a iniquidade, a crueldade ou a corrupção da justiça assim distribuída. A um homem que clama por justiça, Sancho dá uma imagem da justiça pintada, porque, diz ele, "não há nesta ilha outra justiça senão pintada". A uma mulher que denuncia o homem que a seduziu e que se recusa a casar com ela apesar das promessas de casamento que ele fizera, Sancho inflige um castigo cruel: "metam essa mulher na cadeia com uma corrente ao pescoço e grilhões aos pés, bem carregada de ferros, até aparecer o homem com quem ela quer casar". E, quando Sancho deve condenar o seu próprio burro, culpado de ter escoiceado um homem, ele declara (à parte): "o que poderei fazer é não dar execução à sentença".

No mundo do Dom Quixote de Antônio José da Silva, a justiça não existe. Ela é engodo, ilusão, embuste. Como compreeender essa reescrita, forçando os efeitos, do texto de Cervantes? Primeiro, ela permite paródias cômicas da retórica judiciária, com as referências burlescas aos juristas e aos seus códigos: "assim como a ninguém se pode negar a vista, como dispõe o 'text. in 1 . Cæcus, § Tortus ff. de his, qui metit um olho por outro' e com muitos o provam Pão Mole no 'cap. das Côdeas', também da mesma sorte o ouvido se não deve fechar para ouvir os queixosos, como dispõe a 'l. das doze tábuas de Pinho na segunda estância de Madeira, Cod. de Barrotis". Assim, também, a imitação 
ridícula das sentenças dos tribunais, como aquela pela qual Sancho pronuncia a condenação de seu burro. Para alguns, essas facécias inscritas na tradição teatral, que desde sempre ridicularizou juízes e médicos, poderiam prejudicar a compreensão do tom biográfico dessa sátira da justiça presente na peça. É o que indica Machado de Assis: "[...] mesmo admitindo que a alegoria da justiça na Vida de D. Quixote seja o resumo das queixas pessoais do poeta (suposição tão frágil como aquela), a verdade é que os sucessos da vida dele não influíram, não diminuíram a força nativa do talento, nem lhe torceram a natureza, que estava muito longe da hipocondria" (Assis, 1979: 733).

Mais recentemente, porém, Paulo Roberto Pereira destacou a violência dessa sátira sobre a justiça corrupta, e Nathan Wachtel propôs uma base biográfica para os dois motivos essenciais das peças do "Judeu": a metamorfose e o labirinto. Os dois autores referem-se a uma cena de Anfitrião, já comentada por Machado de Assis e José Oliveira Barata, mas com interpretações que a separavam de qualquer referência à vida do autor (Silva, 2007: 317-319). Na sexta cena da Segunda Parte de Anfitrião, Saramago, o criado de Anfitrião, é levado para a prisão do Limoeiro com outros três condenados. Para lhe extorquir dinheiro, estes três o torturam com a mesma técnica utilizada pela Inquisição: a polé, suplício em que o torturado é amarrado com cordas e suspendido até o teto da sala de tortura. Antes de começar o suplício, um dos homens pergunta a Saramago: "Por que te prenderam?" "Por nada", responde o criado e, mais adiante pergunta a seus carrascos: "Que liberdades pode falar quem a não tem?"

Encarcerado na mesma prisão, Anfitrião conta seu infortúnio num recitativo seguido de uma ária. No recitativo, ele declara: "Sorte tirana, estrela rigorosa, / que maligna influis com luz opaca / rigor tão fero contra um inocente ! / Que delito fiz eu, para que sinta / o peso desta aspérrima cadeia / nos horrores de um cárcere penoso, / em cuja triste, lôbrega morada / habita a confusão e o susto mora ? / Mas, se acaso, tirana, estrela ímpia, / é culpa o não ter culpa, eu culpa tenho / mas, se a culpa que tenho não é culpa, / para que me usurpais com impiedade / o crédito, a esposa e a liberdade?"

"Mas, se a culpa que tenho não é culpa, / para que me usurpais com impiedade / o crédito, a esposa e a liberdade?" Não é, sem dúvida, forçar os textos, o fato de ler nesta cena um eco dos sofrimentos passados na prisão, com torturas semelhantes às da Inquisição, bem como a denúncia de uma violência injusta, que leva à fogueira os acusados de um crime que só existe nas obsessões dos seus juízes.

O estudo da Vida do grande Dom Quixote de la Mancha de Antônio José da Silva liga assim três histórias: a história das adaptações teatrais da Segunda Parte de Don Quijote, a história de uma prática teatral poucas vezes reconheci$\mathrm{da}$, a do teatro de marionetes, situado entre o divertimento popular e a ópera, e a história de um dramaturgo, três vezes confrontado com a Inquisição e que viveu a dolorosa condição dos conversos às voltas com suas crenças íntimas e 
as permanentes suspeitas dos Inquisidores. O trágico destino de Antônio José da Silva oferece assim um caso limite para enfrentar a questão da relação entre as experiências de vida e as próprias obras - questão bem aguda e difícil para peças compostas numa época em que a escrita dramática era dependente de histórias já existentes, de motivos tradicionais e de enredos que nada têm de original. Mas será, por isso, impossível encontrar em textos apoiados nessas práticas comuns as marcas de sofrimentos ao mesmo tempo raros e compartilhados?

Artigo recebido para publicação em fevereiro de 2012.

Roger Chartier é professor no Collège de France e na École de Hautes Études en Sciences Sociales (EHESS). Seus últimos livros publicados no Brasil são Inscrever e apagar: cultura escrita e literatura (séculos XI-XVIII) (2007); O sociólogo e o historiador (2011, com Pierre Bourdieu); e Cardenio entre Cervantes e Shakespeare: história de uma peça perdida (2012). 


\section{NOTAS}

Este artigo foi apresentado, na forma de conferência, por Roger Chartier, na abertura dos trabalhos da Cátedra Claude Bernard, no dia 17 de setembro de 2010, no Salão Nobre do Instituto de Filosofia e Ciências Sociais (IFCS) da Universidade Federal do Rio de Janeiro (UFRJ). Chartier foi primeiro titular da cátedra, a convite do Programa de Pós-Graduação em Sociologia e Antropologia (PPGSA) e do Programa de Pós-Graduação em História Social (PPGHIS). [N. E.]

Em Paulo Roberto Pereira, Dom é grafado d. Eu deixei D. [N.T.]

1 Ver a crítica de Stephen Holden, "A Jew trapped in Portuguese terror", New York Times, 8 de janeiro de 1997.

2 Miguel de Cervantes, Segunda Parte del Ingenioso Cavallero Don Quijote de la Mancha, Madri, Juan de la Cuesta, 1615.

3 Le Gouvernement de Sanche Pansa. Comédie. Paris: Antoine de Sommaville e Augustin Courbé, 1642. O texto teve reedição crítica de Caldicott (1981).

4 Dom Quixote de la Manche. Comédie. Paris: Thierry Quinet, 1639. Reeditado com introdução e notas de Della Valle \& Carriat (1979). Sobre essa primeira apropriação teatral da Segunda Parte da "história" escrita por Cervantes, ver Chartier (2011: 110-113).

5 Guyon Guérin de Bouscal, Dom Quichot de la Manche. Comédie. Seconde Partie. Paris: Antoine de Sommaville, 1640. Reeditado com introdução e notas por Marie-Line Akhamlich (1986).

6 O texto da peça está no sitio Le Théâtre de la foire à Paris: texte et documents. Hipertexto de Barry Russell. Disponível em $<$ http://www.theatrales.uqam.ca/foires/play15.html>. Acesso em 30 mai. 2012.

7 Parfaict (1767: 30) indica a respeito dessa peça: "Comédia em três atos e em prosa do Sr. Du Fresny, representada na Quarta-feira 27 de Janeiro de 1694. Não impresso".

8 Sancho Pança gouverneur. Comédia em versos, levada ao Théâtre por M. Dancourt. Paris: Ribou, 1713. Sobre esta peça, ver Blanc (1984: 120-121).

9 Parfaict assim apresenta a peça: "Opéra Comique em dois atos, com um Prólogo, divertimentos e dois vaudevilles pelo 
Sr. Thierry, Música de M. Gilliers, representada na Quintafeira 28 de Agosto de 1727. Não impresso".

10 Ver o catálogo das óperas compostas por Antonio Caldara, disponível em <http://www.haendel.it/compositori/caldara>, e também a lista das edições do libreto de Don Chisciotte in corte della duchessa, disponível em <http://www.itlianopera.org/compositori/C>. Acesso em 30 maio 2012.

11 Miguel de Cervantes Saavedra, Vida y hechos del Ingenioso Cavallero Don Quixote de la Mancha. Nueva edición, corregida y ilustrada con differentes Estampas muy donosas, y apropiadas a la materia. Bruxelas: Emprenta de Juan Mommarte, Impresor jurado, 1662.

12 Miguel de Cervantes Saavedra, Vida y hechos del Ingenioso Cavallero Don Quixote de la Mancha. Nueva edición, corregida y ilustrada con 32 differentes Estampas muy donosas, y apropiadas à la materia. Antuérpia: Geronymo y Juan Bautista Verdussen, 1673.

13 Essas quatro edições são as de María Armenteros em 1674, de Antonio González de Reyes em 1706, de Francisco Laso em 1714 e aquela publicada "a costa de la Hermandad de San Jerónimo" em 1723.

14 Ver também a longa resenha desse livro por Louise K. Stein Journal of the American Musicological Society, 1991, 44/2, p. 332-343).

15 Varey (1957: 237) conclui que "O retábulo de Mestre Pedro pode basear-se numa representação de títeres - de marionetes, de fantoches, de autômatos - que Cervantes vira; mas não é uma reprodução fotográfica de tal representação".

16 Ver a título de exemplo, Ottavio DiCamillo (2005).

17 Ato IV, Cena III: "He bath been since an ape-bearer, then a process-server - a bailliff - then he compassed a motion of the Prodigal Son" (Shakespeare, 1997: 2920).

18 A Vida do grande Dom Quixote de la Mancha é a primeira peça do primeiro volume.

19 Sobre o processo de 1726, ver Frèches (1982). A “abjuração em forma", que Antônio José da Silva não conseguiu assinar, está traduzida e reproduzida nas páginas 41-42.

20 A comédia é atribuída a Antônio José da Silva em suas duas edições modernas: Frèches (1967) e Dines \& Eleutério (2005). 
21 Sobre as obras atribuídas a Antônio José da Silva, ver Perkins (2004: 28-38).

22 Sobre esse segundo processo, ver Frèches (1982: 49-167); Wachtel (2001: 300-313) e o "Traslado do processo feito pela Inquizição de Lisboa contra Antonio Jozé da Silva Poeta Brazileiro", Revista Trimensal do Instituto Histórico e Geographico Brazileiro, Tomo LIX/Parte 1: $1^{\circ}$ et $2^{\circ}$ trimestres. Rio de Janeiro: Companhia Typographica do Brazil, 1896, p. 5-261.

23 Citamos o texto da peça na seguinte edição: Pereira, Paulo Roberto (Introdução, seleção e notas de). Antônio José da Silva, As comédias de Antônio José, o Judeu. São Paulo: Martins Fontes, 2007 (Vida do grande D. Quixote de la Mancha e do gordo Sancho Pança, p. 77-148).

24 Miguel de Cervantes Saavedra, Viage del Parnaso. Madrid: Viuda de Alonso Martín, 1614. Reeditado, com edição, introdução e notas, em Gaos (1973).

25 Sobre este poema, ver Cacciaglia (1993).

26 O livro tem a seguinte dedicatória: "A Memoria de Antonio José Silva, Escriptor Portuguez, Assassinado nas Fogueiras do Santo Officio em Lisboa aos 19 de Outubro de 1739".

27 Com outra intenção, mas na mesma relação entre o destino de Antônio José da Silva e suas obras, convém ler (coisa que não pudemos fazer) o drama histórico em iídiche de Alter Kacyzne, Dem yidns opere [A ópera do judeu], escrito em Varsóvia em 1937, mas só publicado após sua morte em 1941. A peça foi editada no primeiro volume de Alter Kacyzne, Gezamlte Shriftn, Tel Aviv, Ferlag “Ha-Menorah”, 1967, com a primeira obra teatral de Kacyzne, representada em 1925, Dukus, dedicada ao conde Walentyn Potocki, supostamente convertido ao judaísmo e queimado vivo em Vilno em 1749 como Abraham ben Abraham.

\section{REFERÊNCIAS BIBLIOGRÁFICAS}

Akhamlich, Marie-Line (Introdução e notas de). Guyon Guérin de Bouscal. Dom Quichot de La Manche. Comédie. Seconde Partie. Toulouse: Université de Toulouse-Le-Mirail, 1986.

Assis, Machado de. Antônio José. In: Obras completas. Relíquias de Casa Velha. Livro 2. Rio de Janeiro: Nova Aguilar, 1979. 
Azulay, Jom Tob. O judeu. Filme $35 \mathrm{~mm}$, dolby-stereo, $85 \mathrm{~min}$. Coprodução Brasil-Portugal: Animatógrafo, Tatu Filmes, Metrofilme, A \& B Produções, 1996.

Barata, José Oliveira. António José da Silva: criação e realidade. Coimbra: Edição do Serviço de Documentação e Publicações da Universidade de Coimbra/Fundação Calouste Gulbenkian, 1985. (2 vol.)

Préface. In: Léglise-Costa, Pierre (org.). António José da Silva, O Judeu (dit “Le Juif”). Montpellier: Maison Antoine Vitez (Les Cahiers), 2000, p. 12.

Blanc, André. F. C. Dancourt, 1661-1725: la Comédie française à l'heure du soleil couchant. Tübingen: Gunter Narr, 1984.

Brito, Manuel Carlos de. Opera in Portugal in the eighteenth century. Cambridge/Nova York: Cambridge University Press, 1989.

Cacciaglia, Norberto. Il viaggio di Parnaso di Cesare Caporali. Perúgia: Guerra, 1993.

Caldicott, C. Edric J. (edição crítica de). Daniel Guérin de Bouscal. Le gouvernement de Sanche Pansa. Comédie. Genebra: Librairie Droz, 1981.

Canavaggio, Jean. La dimensión autobiográfica del Viaje del Parnaso. Bulletin of the Cervantes Society of America, 1981, I/1-2, p. 29-41.

Caporali, Cesare. Il viaggio in Parnaso. In: Raccolta di alcune rime piacevoli. Parma: 1582.

Castelo Branco, Camilo. O judeu. Romance histórico. Porto: Viúva Maré, 1866.

Cervantes Saavedra, Miguel de. Viage del Parnaso. Madri: Viuda de Alonso Martín, 1614.

Miguel de. Segunda Parte del ingenioso cavallero Don Quixote de la Mancha. Madri: Juan de la Cuesta, 1615.

, Miguel de. O Engenhoso fidalgo Dom Quichote de la Mancha. Lisboa: Typographia Rollandiana, 1794.

Miguel de. Don Quijote de la Mancha. Edición del Instituto Cervantes, dirigida por Francisco Rico. Barcelona: Instituto Cervantes/Crítica, 1998, II, XXV-XXVII, p. 839-857.

Chartier, Roger. Cardenio entre Cervantès et Shakespeare: histoire d'une pièce perdue. Paris: Gallimard, 2011. 
Della Valle, Daniela \& Carriat, Amédée (Introdução e notas de). Guyon Guérin de Bouscal. Dom Quixote de la Manche. Comédie. Genebra/Paris: Librairie Slatkine/Librairie Champion, 1979.

DiCamillo, Ottavio. Consideraciones sobre La Celestina y las instituciones dramatúrgicas del humanismo en lengua vulgar. In: DiCamillo, Ottavio \& Neil, John Neil (orgs). La Celestina, 1499-1999. Selected papers from the International Congress in Commemoration of the Quincentenial Anniversary of La Celestina. Nova York: Hispanic Seminary of Medieval Studies, 2005.

Dines, Alberto \& Eleutério, Victor. Antônio José da Silva, O Judeu em cena. El prodigio de Amarante/O prodígio de Amarante. Primeira edição bilíngue e comprovação de autoria. São Paulo: Edusp, 2005.

Forestier, Georges \& Bourqui, Claude. Registre de la Grange. In: Molière. Euures complètes. Tomo I. Paris: Gallimard (Bibliotèque de La Pléiade), 2010, p. 1029-1052.

Frèches, Claude-Henri (edição crítica de). António José da Silva. El prodigio de Amarante. Lisboa/Paris: Bertrand/Les Belles Lettres, 1967. António José da Silva et l'Inquisition. Paris: Fundação Gulbenkian, 1982.

Gaos, Vincente (edição, Introdução e notas de). Miguel de Cervantes. Poesías Completas, I: Viaje del Parnaso y Adjunta al Parnaso. Madri: Castalia, 1973.

Gossett, Suzanne (org.). Ben Jonson. Bartholomew Fair. Act V. Manchester/Nova York: Manchester University Press, 2000. Gomes, André Luís. Marcas de nascença: a contribuição de Gonçalves de Magalhães para o teatro brasileiro. São Paulo, Antiqua, 2004.

Grimarest, Jean-Léonor de. La vie de Monsieur de Molière. Paris: Jacques Le Febvre, 1705.

Jurkowski, Henryk. A history of European puppetry from its origins to the end of the 19th century. Lewiston/Queenston/ Lampeter: The Edwin Mellen Press, 1996.

Kacyzne, Alter. Gezamlte šhriftn. Tel Aviv: Ferlag "Ha-Menorah", 1967. (vol. 1) 
Lima, Mariângela Alves de (org.). Domingos José Gonçalves de Magalhães. Tragédias. São Paulo: Martins Fontes, 2005.

Martín, Manuel Garcia (org.). Fragoso, Juan de Matos; Diamante, Juan Bautista \& Vélez de Guevara, Juan. El Hidalgo de la Mancha. Salamanca: Ediciones Universidad de Salamanca, 1982.

Machado, Diogo Barbosa. Bibliotheca lusitana historica, critica e cronologica: na qual se comprehende a noticia dos authores portuguezes, e das obras, que compuseraõ desde o tempo da promulgaçaõ de Ley de Graça até o tempo prezente. Lisboa: Antonio Isidoro da Fonseca, [1741] 1965. (vol. I)

Magalhães, Domingos José Gonçalves de. Antônio José ou o poeta e a Inquisição. Rio de Janeiro: Empresa Tipográfica Dous de Dezembro, 1838.

Maupoint. Bibliothèque des Théâtres. Paris: Laurent-François Prault, 1733.

Ottonelli, Giovanni Domenico. Della christiana moderatione del theatro. Florença: Giovanni Antonio Bonardi, 1645.

Parfaict, Claude. Dictionnaire des théâtres de Paris. Paris: Rozet, 1767. (vol. V)

Pereira, Paulo Roberto. Dramaturgia e Inquisição. In: Silva, Antônio José da. As comédias de Antônio José, O Judeu. São Paulo: Martins Fontes, 2007.

Perkins, Juliet. A critical study and translation of António José da Silva's Cretan Labyrinth. Lewinston/Queenston/Lampeter: The Edwin Mellen Press, 2004.

Santareno, Bernardo. O Judeu: narrativa dramática em três actos. Lisboa: Ática, 1966.

Shakespeare, William. The Winter's Tale. In: Greenblatt, Stephen (org.). The Norton Shakespeare: based on the Oxford Edition. Nova York/Londres: W. W. Norton \& Company, 1997, p. 2873-2953.

Shershow, Scott Cutler. Puppets and "popular" culture. Ithaca/ Londres: Cornell University Press, 1995.

Silva, António José da. Theatro Comico Portuguez ou Collecçaõ das Operas Portuguezas, Que se representaraõ na Casa do Theatro publico do Bairro Alto de Lisboa. Lisboa: Regia Officina Sylviana e Academia Real, 1744. (2 vol.) 
I 80

. Anfitrião ou Júpiter e Alcmena. In: As comédias de Antônio José, o Judeu. (Introdução, seleção e notas de Paulo Roberto Pereira). São Paulo: Martins Fontes, 2007, p. 317-319.

. As comédias de Antônio José, o Judeu. (Introdução, seleção e notas de Paulo Roberto Pereira). São Paulo: Martins Fontes, 2007.

Varey, John Earl. Historia de los títeres en España (desde sus orígenes hasta mediados del siglo XVIII). Madri: Revista de Occidente, 1957.

Wachtel, Nathan. La foi du souvenir: labyrinthes marranes. Paris: Seuil, 2001.

_. La logique des bûchers. Paris: Seuil, 2009. 


\section{Palavras-chave: Resumo:}

Antonio José da Silva; Este estudo da peça Vida do grande Dom Quixote de la Mancha Dom Quixote; e do gordo Sancho Pança, de Antônio José da Silva liga três

Teatro de marionetes; histórias: a história das adaptações teatrais da Segunda Inquisição; Cristão-novo Parte de Dom Quixote, a história de uma prática teatral poucas vezes reconhecida, a do teatro de marionetes, situado entre o divertimento popular e a ópera, e a história de um dramaturgo, três vezes confrontado com a Inquisição e que viveu a dolorosa condição dos conversos às voltas com suas crenças íntimas e as permanentes suspeitas dos Inquisidores. O trágico destino de Antônio José da Silva oferece assim um caso limite para enfrentar a questão da relação entre as experiências de vida e as próprias obras.

\section{Keywords: Abstract:}

Antonio José da Silva;

Dom Quixote; Marionette theater; Inquisition; New-christians.
This study of the play Vida do grande Dom Quixote de la Mancha e do gordo Sancho Pança by Antônio José da Silva connects three histories: the history of theatrical adaptations of the second part of Dom Quixote; the history of a frequently neglected theatrical practice, that of the marionette theater, situated between popular entertainement and the opera; and the history of a playwright, who was tried three times by the Inquisition, and endured the painful condition of conversos coping with their intimate beliefs and the permanent suspicion of inquisitors. The tragical destiny of Antônio José da Silva offers a drastic example of the question bearing upon the relationship between life experiences and the works themselves. 